\title{
32. TENTATIVE CALIBRATION OF SITE 398 AND SPECIAL PROCESSING OF PARTS OF LINES GP-19 AND GP-23
}

\author{
R. Bouquigny and C. Willm, Institut Français du Pétrole, Rueil-Malmaison, France
}

\section{INTRODUCTION}

The following two studies have been undertaken to provide a better interpretation of the seismic lines and the best correlation between geological events and seismic markers:

1) Computation of synthetic seismogram from the values of the acoustic impedances recorded of the drill site.

2) True amplitude processing of line GP-19 (from SP-300 to SP-800) and line GP-23 (from SP-400 to SP-750), velocity analysis every 10 shot points, migration and computation of PDIA (acoustic impedance pseudologs).

\section{SYNTHETIC SEISMOGRAM}

The synthetic seismogram technique is an ideal way of linking geological well data with seismic information, provided that sediment velocities and the densities are known with accuracy along the entire stratigraphic column. The computation of the reflection coefficients from sonic and density logs is easy; the integrated timing bips of the sonic are used to sample the reflection coefficients every 2 or 4 milliseconds and, if available, calibration shooting is used to test and correct the time scale. The convolution of the reflection coefficient time series by an appropriate seismic impulse develops the synthetic seismogram which should correlate well with the seismic traces recorded close to the drill site. It is then possible to draw the stratigraphic column on the seismic line with accuracy.

Velocity, density, and acoustic impedance measured on Site 398 cores are the only available data. Therefore, the depth to time conversion is very difficult and the result is not very accurate. However, the synthetic seismogram shown on Figure 1 fits well with the seismic section close to the drill site, except for a peak inside the black shale formation. This is probably due to the thickness of the bed generating a high acoustic impedance which has been exaggerated by the timesampling process.

The main difficulty in the computations is the presence of several abnormally high values. It is difficult to determine the thickness of the corresponding beds and an examination of the lithological description is rarely a help. A few isolated high values were discarded because they resulted in peaks not seen on the seismic section.

Two or three high amplitude peaks of the synthetic record are worthy of discussion, most notably the one appearing at 550 milliseconds, which is near a chert intercalation.

To make the sampling, three different vertical velocities were assumed:

1) $1765 \mathrm{~m} / \mathrm{s}$ from sea bottom to 371 meters $(420 \mathrm{~ms}$, two-way time),

2) $2185 \mathrm{~m} / \mathrm{s}$ from 371 to 1462 meters (1418 ms),

3) $3587 \mathrm{~m} / \mathrm{s}$ below 1462 meters.

These velocities were derived from the velocity analyses and are not very different from the one adopted by C.A. Williams. The largest discrepancy between the two velocity functions is $35 \mathrm{~ms}$ of two-way time at the purple horizon. The velocity adopted between the green and purple horizons $(1890 \mathrm{~m} / \mathrm{s})$ seems too low if the new set of velocity analyses are considered.

Except for the reflector at $550 \mathrm{~ms}$, the green, purple, yellow, and orange horizons actually correspond to the four most outstanding reflections on the synthetic record. Below orange horizon, the velocity variations are large and correspond to numerous reflections. This is in accordance with the general aspect of the section below the transparent zone corresponding to lithologic Sub-units $4 \mathrm{~A}$ and $4 \mathrm{~B}$ (1.4 s below sea bottom close to the drill site.

The main result of this study is the correlation between the seismic data and lithology, as shown on Figure 1. There the lithologic column drawn at the same vertical time scale as the seismic is correlated by horizontal lines to the main markers of the synthetic seismogram. It is difficult to link a geological event such as a hiatus or a prominent lithologic marker with a seismic reflector because the seismic resolution is poor and an individual marker corresponds to a thickness of not less than $\mathbf{5 0}$ meters. The seismic image is the result of the acoustic impedance variations in a window as wide as the seismic pulse used and not of a single change of lithology. Nevertheless, the different lithological units are well defined in a broad sense.

\section{PROCESSING OF LINES GP-12 (SP-300 TO SP-800) AND GP-23 (SP-400 TO SP-750)}

The special processing on line GP-19 from SP-300 to SP- 800 and on line GP-23 from SP-400 to SP-750 was undertaken to define the vertical partition and lateral variations in acoustic impedance. This would help in interpreting the seismic data in terms of lithology.

The acoustic impedance pseudo-log technique (socalled PDIA, i.e., "pseudo-diagraphie d'impédance 


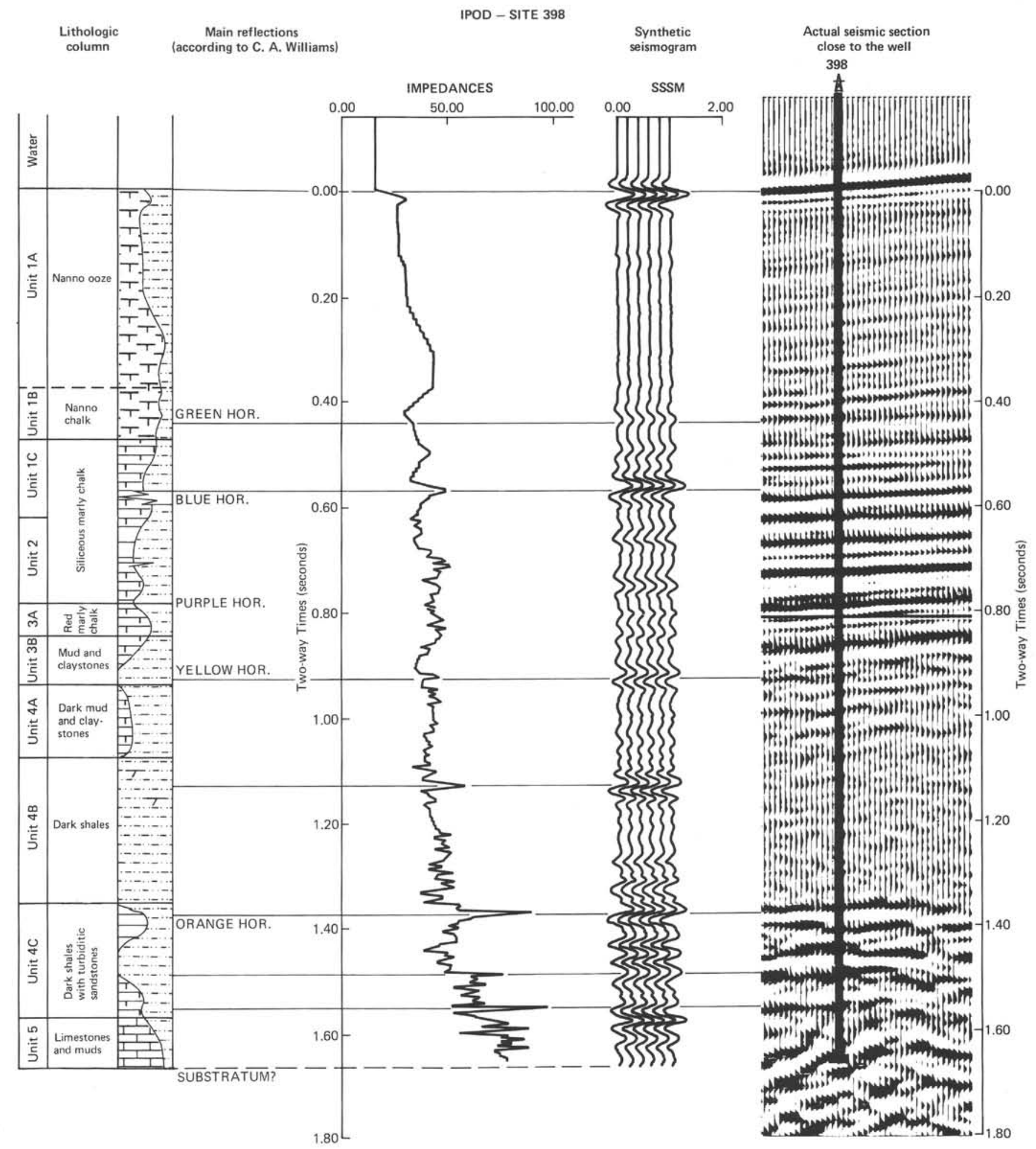

Figure 1. Correlation between lithology, acoustic impedance, synthetic seismic trace, and seismic traces near the well site.

acoustique") was developed by IFP geophysicists and geologists four or five years ago. A few papers have been published (Lavergne, 1975; Lavergne and Willm, 1977; Becquey et al., in press) giving details of the technique and examples of its application to oil or gas fields as well as oceanographic seismic lines including JOIDES lines for DSDP Site 372, Leg 42 in the western Mediterranean Sea. 
The processing was made in two steps: reprocessing of the seismic sections, and computation of acoustic impedances.

\section{REPROCESSING THE SEISMIC SECTIONS}

The main differences between previous processing (Figures $2 \mathrm{~B}$ and $3 \mathrm{~B}$ ) and the new one (Figures $2 \mathrm{~A}$ and 3A) are as follows:

1) Improvement of velocity control by the mean of velocity analysis every 10 shot points.

2) Amplitude preservation, instead of automatic gain control, providing better contrast between weak and strong reflections. Theoretically, after application of this process, the ratio between the amplitude of two reflections is the same as the ratio between the reflection coefficients of these two reflections. This is necessary for the computation of acoustic impedances and to increase differences between the various formations.

3) Application of the wave-equation migration program to attenuate the diffraction hyperbolae and to place the dipping reflections at their actual location.

In both cases, a predictive deconvolution was applied before stacking in the first processing, and after stacking in the last one (Figures $2 \mathrm{~A}$ and $3 \mathrm{~A}$ ).

The comparison between the previously processed sections and the reprocessed sections is shown in Figure 2 for line GP-19 and Figure 3 for line GP-23. The improvement is obvious and it is certainly much easier to interpret the latter. The shallowest part of these sections is improved mostly by the amplitude contrast obtained, so there is better separation of the different formations. The deepest part of the section is completely transformed by migration. The reorganization of the reflections gives a good perspective of the main tectonic features below the Late Cretaceous major unconformity.

The sea-floor morphology is also improved greatly on the migrated section, especially on the slope of the hill where it is possible to recognize erosion channels and terraces.

Below the sea floor the now well-known formations of this area are easily recognizable:

a) Rather transparent upper interval (Formation 1A) with weak reflectors affected by low dips.

b) Layered sequence with strong reflectors locally affected by internal unconformities (Formations $1 \mathrm{~B}$ and 2 ); this sequence is itself unconformable on Formation 3.

c) Transparent zone (Formation 3, "Black Shales") is practically absent of reflections and shows rapid variations of thickness related to the underlying relief.

d) Underlying series show numerous reflections, especially in the upper part, and relatively intense and faulted sequence (Formation 4).

\section{COMPUTATION OF ACOUSTIC IMPEDANCES}

The computation of acoustic impedances is made in two steps:

1) Inversion of the seismic traces by the algorithm described by Lavergne (1975) and by others.
2) Calibration of the result, using information on densities and velocities known either by direct measurements on cores or by velocity analysis, made every 10 shot points.

The results are displayed in Figures 4 and 5, and in color in the frontispiece to this volume. The black and white color density showing the variations of acoustic impedances. The color impedance scale (shown on the bottom of Figures 4 and 5) gives the correspondence between the color and the acoustic impedance value.

In this study, an average density for each unit was estimated from the data recorded in the Site Report (this volume). Lateral variation of the velocities has been introduced by using different velocity functions applied at different places with linear interpolation between the points of applications. These velocity functions are similar to the ones estimated by C.A. Williams, with a regular increase of velocity with depth except for the "Black Shales" Formation 3, where velocity and density are lower than in the overlying formations. This anomaly has been taken into account and is seen in the frontispiece color-rendition of Figures 4 and 5 (green for Formation 3 as for Formation 1, whereas Formation 2 is yellow and orange). An exception is apparent in the central part of line GP-19 (yellow in Formation 3).

The color display helps separate the different units and facilitates interpreting the geology: the substratum with high acoustic impedance (i.e., raw turbiditic material filling the troughs in red-orange during Early Cretaceous time), then the pelagic deposits of Units 4 to 1 with low acoustic impedance (green and yellow).

\section{CONCLUSION}

As explained above, the knowledge of the velocities is critical to good correlation between geology and seismicity. In the case of IPOD Site 398, the lack of continuous velocity control and of calibration shooting is a handicap. Fortunately, it is possible to calibrate the depth to time conversion in fitting the base of the Black Shales formation with the orange marker, but still the question remains to know what part of the Sub-unit $4 \mathrm{C}$ is seen by the seismic. Our interpretation is that the orange marker does correspond to the turbiditic layer on the top of the Sub-unit 4C (Cores 104 through 106), since going deeper would give unacceptably high velocities above. Therefore, it can be considered that the last 50 meters of the hole have been drilled through the strongly dipping reflectors of the acoustic substratum.

For the future sites, the use of Schlumberger logging tools will improve the results, but calibration shooting should be undertaken as well.

\section{REFERENCES}

Becquey, M., Lavergne, M., and Willm, C., in press. Acoustic impedance logs computed from seismic traces, Geophysics.

Lavergne, M., 1975. Pseudo-diagraphie de vitesse en offshore profond, Geophysical Prospecting, v. 23.

Lavergne, M. and Willm, C., 1977. Inversion of seismograms and pseudo-velocity logs, Geophysical Prospecting, v. 25. 


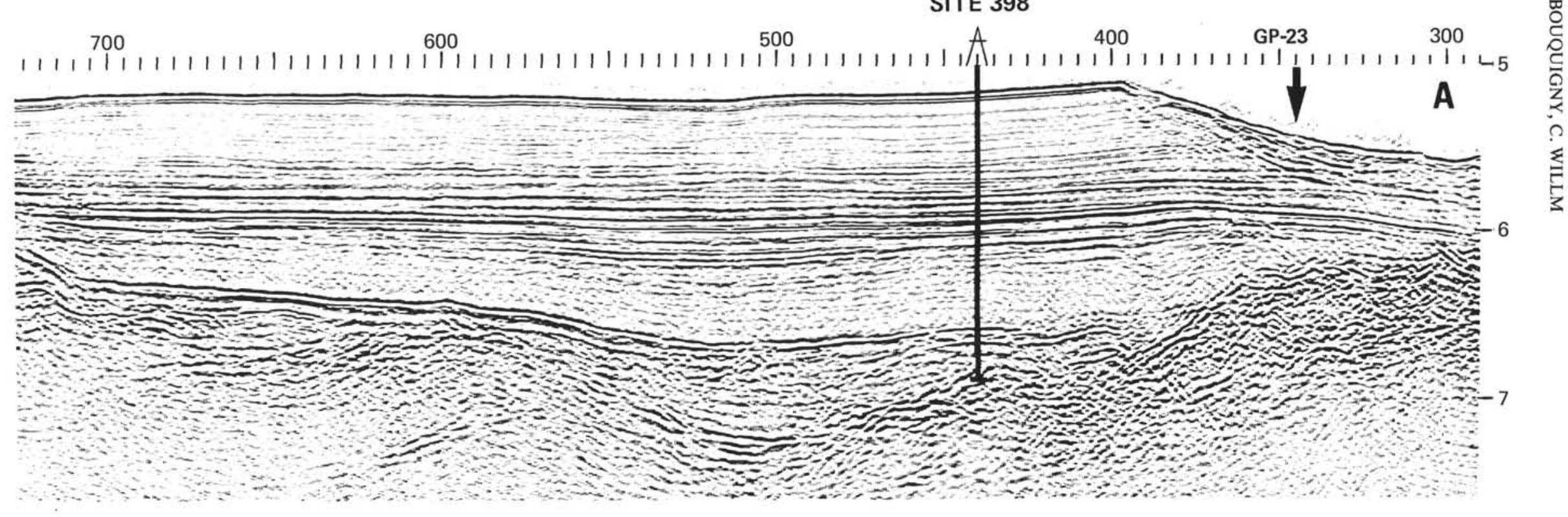

WNW

LINE GP-19

SITE 398

ESE

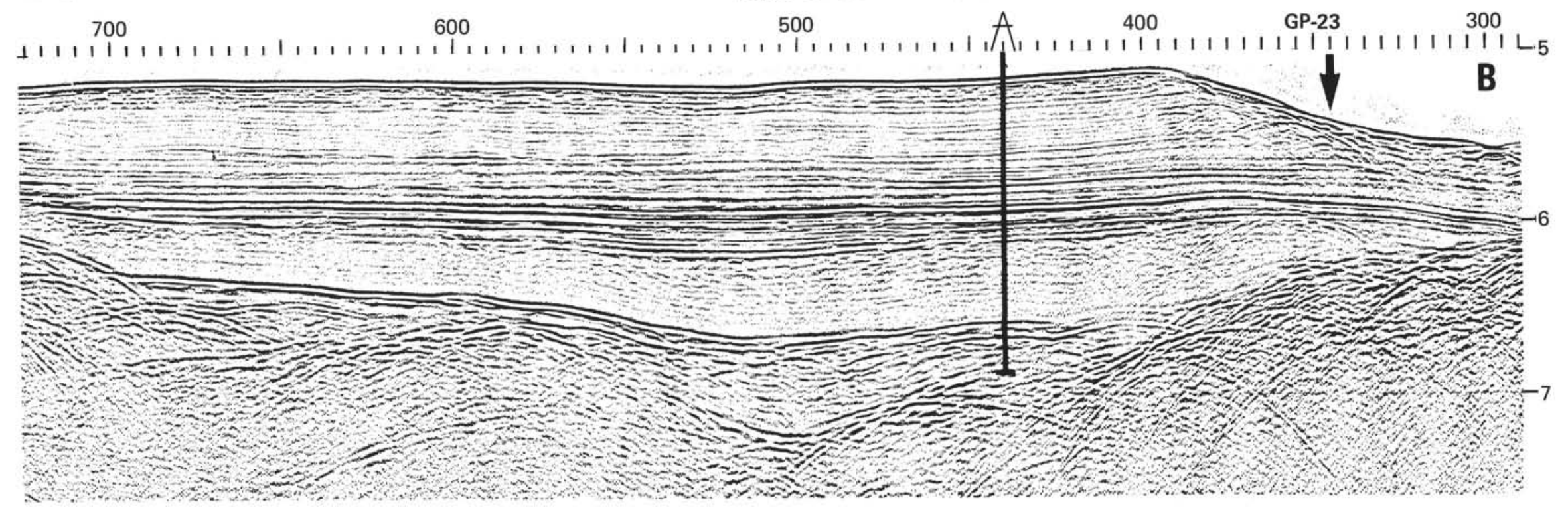

Figure 2. Line GP-19, comparison between reprocessed section (A) and previously processed section (B). 

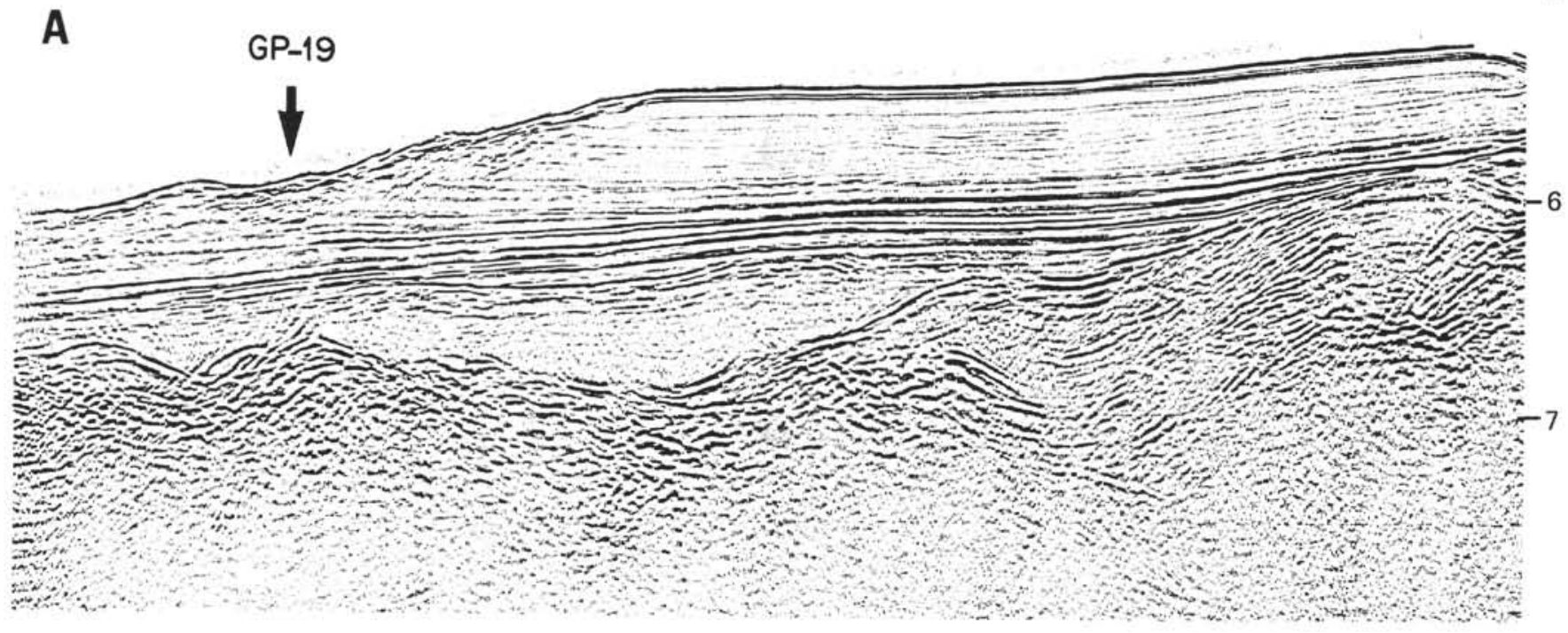

SSW

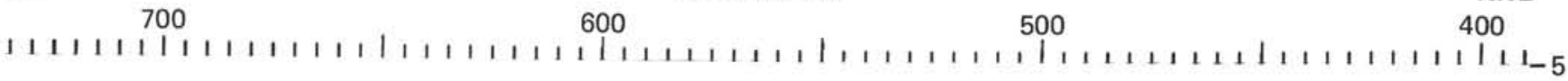

LINE GP-23

NNE

$11111111111111111111111111111111111111,1111111111111111111111111111111-5$

$11111111111111111111111111111111111111,1111111111111111111111111111111-5$

$11111111111111111111111111111111111111,1111111111111111111111111111111-5$

B

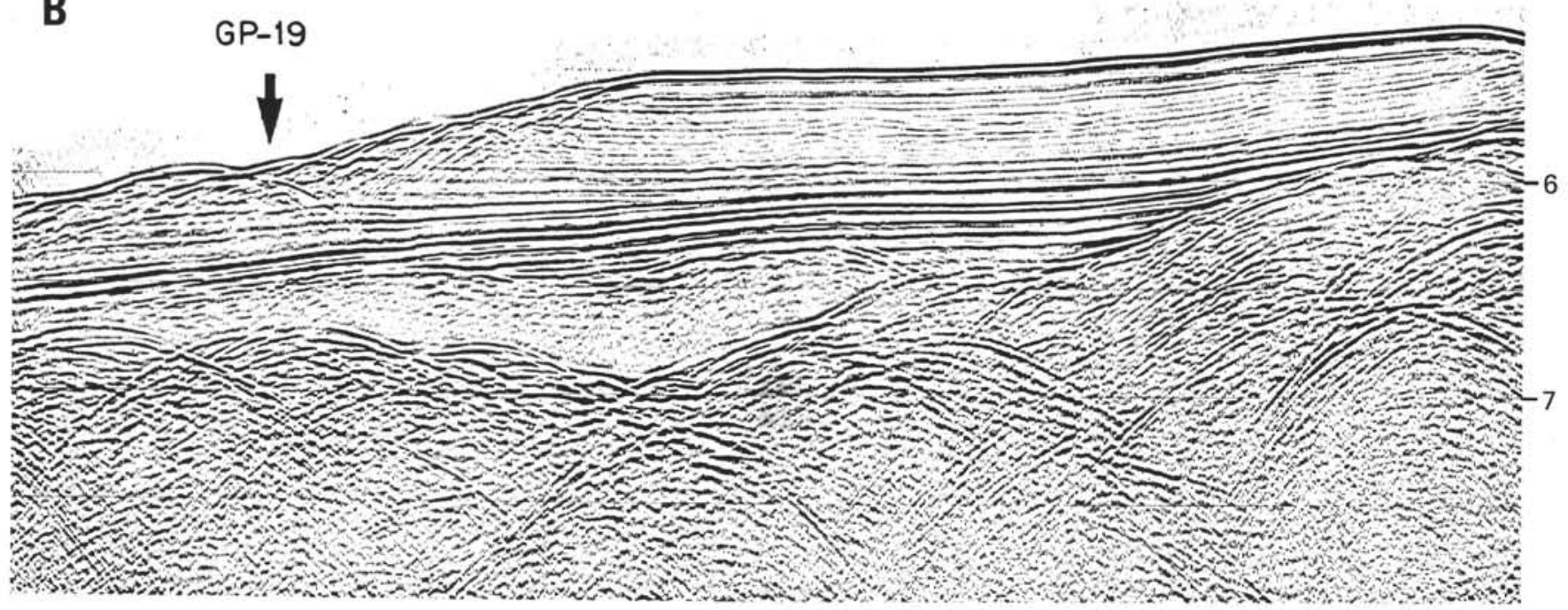

Figure 3. Line GP-23, comparison between reprocessed section $(A)$ and previously processed section $(B)$. 


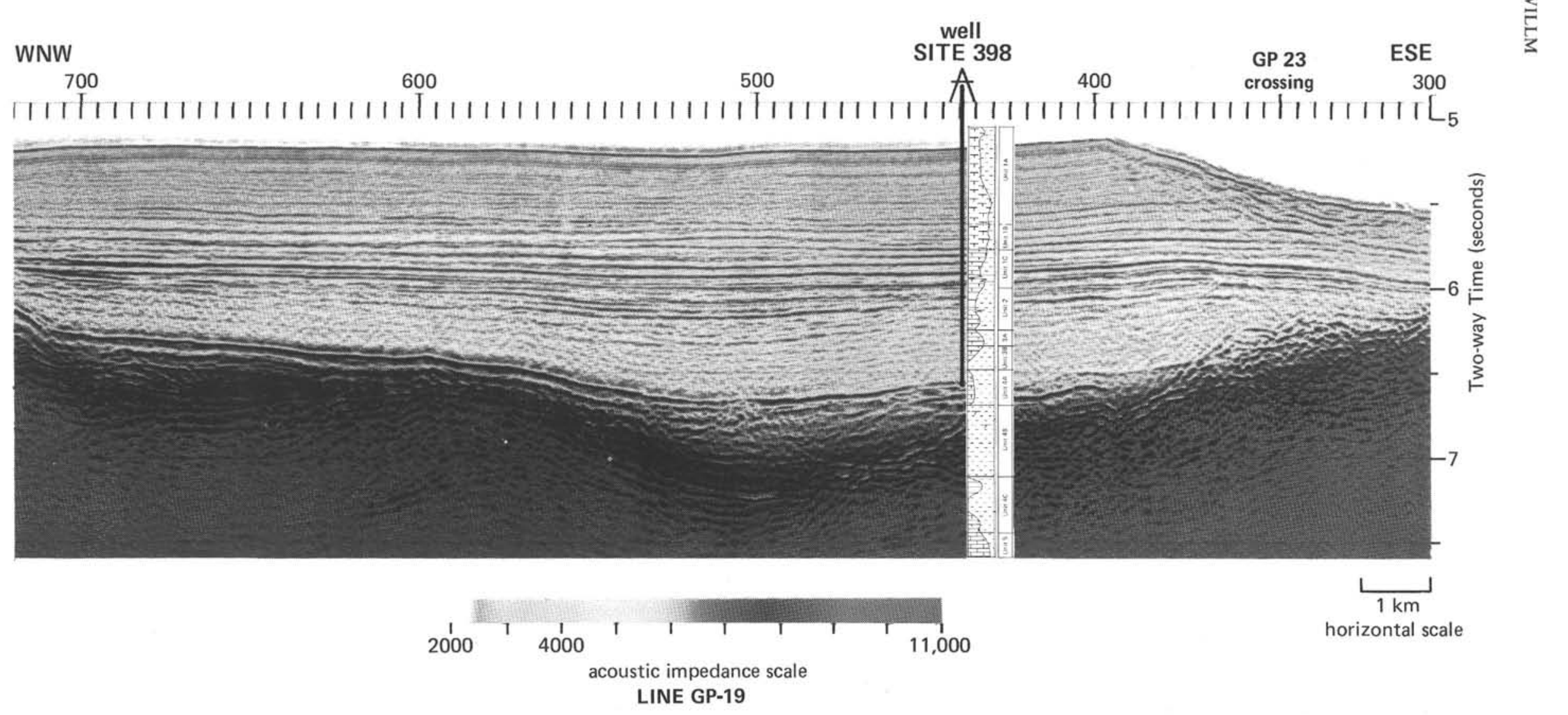

Figure 4. Acoustic impedance time section, line GP-19, Site 398. 

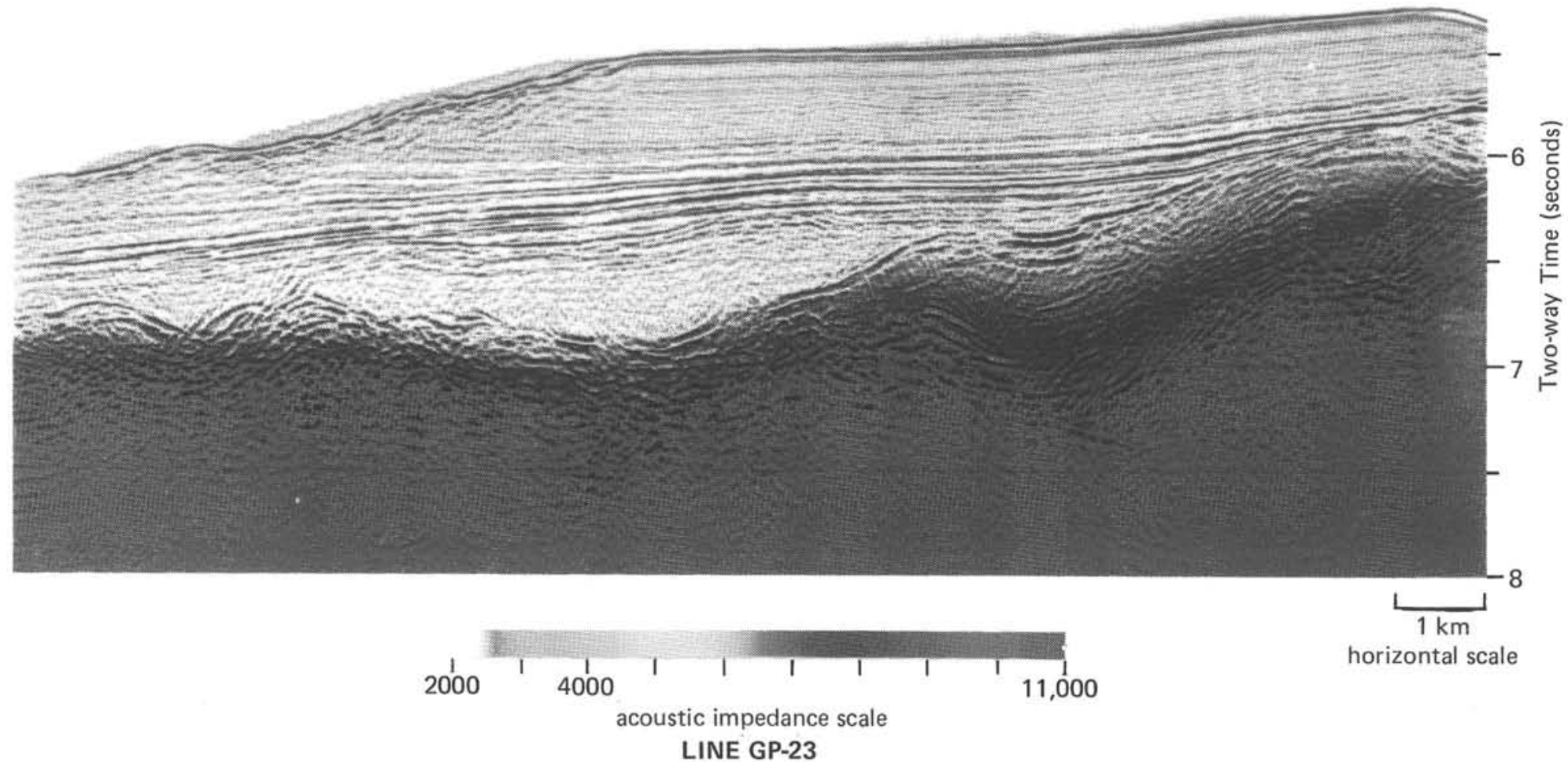

horizontal scale LINE GP-23

Figure 5. Acoustic impedance time section, line GP-23, Site 398. 